\title{
La Obra Filosófica de Don Alejandro Deustua.
}

En la celebración del $90^{\circ}$ aniversario de su nacimiento, el doctor Alejandro Detustua ha recibido no sólo el homenaje de sus discípulos sito lambién, y muy merecidamente la adhesión y el reconocimiento de cuantos se interesan por el grave y profundolpooblemadde laceducación en el Perú y por el senticlo de farculturacnacional A A las expresiones de ese sentimiento unánime queremos unir este breve estudio consagrado a la obra filosófica de Deustua y a su influencia en la universidad. Obra e influencia que constituyen sin duda uno de los acontecimientos más trascendentales y significativos en la vida espiritual de nuestro país.

Hay en la historia intelectual del doctor Deustua, una interesante progresión de perspectivas. De los estudios psicológicos elévase a las concepciones morales y obtiene dentro de ellas, una visión cada vez más penetrante y comprensiva de nuostras aspiraciones superiores. En ese plano, al interrogarse ansiosamente sobre los fundamentos de la ac- 
tividad ideal, y sobre los valores supremos de la misma, encuentra aquéllos y éstos en la libertad interior. Con lo cual, todas las obras del espíritu transfigúranse a sus ojos, al recibir, por virtud de la actividad de donde emergen, el sello estético que marca todas las libres creaciones de la vida.

Pero su obra ha desbordado los marcos de una labor meramente especulativa: con profunda conciencia de nuestras modalidades coléctivas, ha planteado el problema de la educación nacional y ha procurado resolverlo en términos donde se traducen juntamente la alta inspiración filosófica y la aguda visión nacionalista.

Procuraré seguir el proceso relacionado con el medio universitario en que se ha desenvuelto. El doctor Deustua inicia su intervención en nuestra vida cultural el año de I 869 en que fué nombrado Profesor Adjunto de Filosofía en la Facultad de Letras. En. I 882 se le eligió Profesor Adjunto también de Literatura General y Estética. En I884 fué ya catedráticoi principat deola misina asignatura y finalmente, en IgO2 entróo a regentàrcel curso de Filosofía Subjetiva. Desde entonces no ha dejado de prestar a la Facultad de Letras, a la Universidad y al país el valioso concurso de sus luces y de su absoluta consagración a los trabajos del espíritu.

Llamado a dictar los cursos de Estética y Filosofía Subjetiva en momentos de crisis universitaria dedicó a su enseñanza, al par que una fuerte inteligencia, una poco común laboriosidad. Cuando ingresó a la Facultad de Letras, lo que podríamos llamar el pensamiento filosófico se bifurcaba entre ùn positivismo anémico y un racionalismo decrépito. A estas actitudes sin virtualidad hubo de oponer la inspiración de una filosofía animada por el sentimiento de la vida libre y creadora, y por la confianza inquebrantable en la eficacia de los valores morales en la evolución social. 
La obra de Deustua con sus afirmaciones psicológicas y metafísicas representó en conjunto una reacción saludable contra el intelectualismo que aquí dominaba tanto al apreciar el papel de la inteligencia en la vida consciente como al determinar su valor de actividad cognoscitiva. Negando a la inteligencia, como lo hizo el doctor Deustua, la preponderancia que la vieja psicología le asignaba, hay que conferírsela al sentimiento y a la voluntad. En ambos casos se desplaza la actividad central de la conciencia, trasladándola del mecanismo lógico a la espontaneidad de sus elementos subjetivos. La vida psíquica aparece como una fuerza que al propio tiempo es expansiva y es sintética, y de esta suerte se prepara el camino para llegar a concebirla como un fluir esencialmente creador y libre.

Es así como desde su inicial inspiración wundtiana, la psicología de Detustua evoluciona hasta incorporarse en la concepción de Los Datos Inmediatos de la Conciencia. Para Bergson la acividad interiar es duna continuidad indistinta, algo como una melodía ininter rumpida, como una corriente inagotable. La libertad y la conciencia se identifican porque la conciencia es duración, es decir, cambio incesante, brotar de realidades imprevisibles, nuevas, líricas. De este modo la libertad es concebida como el impulso central de la existencia y su intuición, resulta necesaria para plantear y resolver los problemas humanos en términos verdaderamente vitales y fecundos.

En moral ha seguido el doctor Deustua la misma dirección voluntarista. Pero él concibe la voluntad moral no como una fuerza ciega sino como un impulso dotado de dirección y de finalidad. Por eso adoptando una posición independiente, así del puro moralismo intelectualista como del inmoralismo absoluto, cree que la voluntad libre es capaz de erigir un ideal y perseguirlo, progresando de las so- 
licitaciones inferiores de la sensualidad y del interés, a los goces elevados de la actividad altruista y generosa. E1 progreso de la vida moral es un progreso en intensidad y en amplitud, es un enriquecimiento continuo del que se benefician no sólo el individuo que lo alcanza, sino la sociedad en cuyo seno se produce. $Y$ el ideal es el de una felicidad superior, de una armonía entre la vida interior de la persona y la vida social. $\mathrm{Ni}$ el absoluto abandono de sí mismo que suprime al individuo, ni el egoísmo puro que ante la afirmación del Unico suprime a todos los demás. Debemos buscar en fin, una forma de vida en que se sumen la fuerza que triunfa y la visión ideal que orienta.

En, la íntima evolución del yo profundo de donde surge dl acto verdaderamente morat, se identifican según Deustua la solidaridad y la libertad. Doctrina amplia, que confiriendo a la acción libre un contenido simpático y social, prescribe a la vida la generosidad y el entusiasmo, pero que

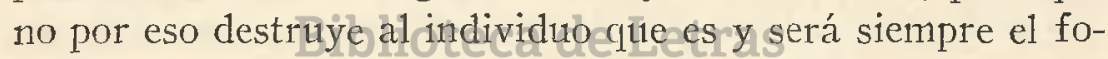
co más rico dejurradiaciém espiritual.so Concepción nueva fundada en una honda percepción de la genuina actividad consciente. En ella todo lo que es libre es expansivo y todo lo que es expansivo es solidario porque es una contribución de toda el alma al acerbo de las riquezas ideales.

Cuando la inclinación hacia los otros lleva hasta la total renuncia de sí mismo, transfigúrase el alma con la majestad de lo sublime y la simple moralidad queda superada por la infinita ascensión de la vida estética.

Es en la disciplina de lo bello donde el doctor Deustua ha ejercitáto una dedicación más asidua y una originalidad mayor. Griado por la intuición de la actividad creado$\mathrm{ra}$, ha discriminado con admirable sagacidad aquello que constittuye la esencia, de lo que está formado por elementos adventicios y extraños en la composición del hecho estético. 
$Y$ así, continuando en su dirección psicológica fundamental, ha concebido una vasta teoría, que no sólo salva la independencia de la actividad estética, sino que la erige en la fuente de todas las aspiraciones superiores.

Desarrolla esos motivos en su obra La Estética de la Libertad 1lena de interesantes sugestiones y sostenida por un vigoroso temperamento filosófico. Son páginas que traducen, junto con la visión psicológica, el esfuerzo metafísico y la emoción de la belleza. Son páginas hermosas, plenas, inspiradas, que podemos exhibir como los exponentes genuinos de nuestra cultura filosófica.

Trataré de sintetizar su contenido. En la nueva filosofía que el doctor Deustua adopta y desenvuelve, el espíritu es ante todo creación,-voluntad expansiva y libre. Es una fuente vital inagotable de donde emergen las imágenes del arte como realizaciones de sus virtualidades más profundas. Si vivir es crear, la imaginación que es creadora por esencia es la vida mistina. Porelozuad, dilatando nuestra intima experiencia, al vasto espectáculo del cosmos, contemplaremos las imágenes innumerables como manifestaciones de una suprema fantasía artística. La estética vuélvese entonces metafísica, y nos ofrece con la visión movible de nuestro mundo interior, la impresión, inefable de la inquietud universal. Fué sin duda, la misma inspiración quien produjo el sublime pensamiento de Schelling: El arte abre el santuario donde lo particular y lo universal arden en una misma llama inextinguible.

El espíritu es memoria, dice Bergson, a lo cual agregaría Deustra dentro de la misma doctrina: pero la memoria que no es una simple repetición pasiva de imágenes sino una creación continua, es en el fondo la propia imaginación que adapta, inventa, suscita y transforma el recuerdo que es una cosa del pasado en una realidad fresca y presente 
donđe se agita toda la ansiosa actualidad del yo. Nace de allí la equivalencia entre espíritu, imaginación y libertad que constituye para Deustua la última realidad de la vida estética.

Este concepto de la actividad imaginativa importa la extensión de la categoría estética a todas las invenciones en que se traduce la libertad del espíritu. Mas ello no excluye la necesidad de distinguir el arte de otras formas de vida espiritual, ya que la libertad tiene grados de mayor o menor eficacia y amplitud. La actividad libre se nos ofrece desde luego, trabajando por vencer, por organizar la materia inerte y perfeccionando en los azares de la lucha las disciplinas científicas y las utilitarias. En un plano más alto la encontramos suscitando el ideal moral en que se identifican la libre expansión de la persona con la acción solidaria y simpática. En la vida religiosa por último, se presenta proyectando las exigencias superiores en una perspectiva ilimitada y componiendo alli la imagen ideal de Dios. Pero la actividađlibręêauiere todayía algo más y crea el arte bello, donde sejorealiza el nalor de todos los valores, el cual es la pureza absoluta, la más incontaminada libertad.

La ciencia busca la verdad y la verdad es el orden. La economía liga los impulsos espontáneos al mecanismo de las fuerzas materiales o sociales. En la moral la ley es una expresión de libertad, pero en cierto modo es también su límite. La propia liberación religiosa piensa Deustua, no 1leva al individuo a la plena realización de sí mismo, puesto que tiende a ábismarlo en el seno de Dios. Sólo la imaginación artística forja ideales libres de todo temor reverencial, no tiene sobre sí, ni el marco inflexible de la ley moral ni los designios sobrehumanos de Dios. Pero hay más: la actividad artística propone las nuevas formas de sueño o de vida que después consagrarán las morales y las religio- 
nes y las impondrán revistiéndolas de un, prestigio inmemorial y místico. $\mathrm{Y}$ así en el fondo de las instituciones más viejas, de las creencias más venerables, palpitan la misma ansiedad renovadora, la misma efervescencia espiritual.

Ejercitando en el dominio estético su crítica del intelectualismo, estudia el doctor Deustua las clasificaciones y. los grados estéticos. Los denuncia como deformaciones provenientes de aplicar las categorías abstractas de la lógica a una actividad libre, sintética y concreta que abraza en un solo movimiento y funde en una sola realidad el contenido y la forma, el sujeto y el objeto, que es inclasificable por que es libre y que en la infinita variedad de sus manifestaciones ostenta el sello siempre auténtico y rebelde de una inspiración original. A la noción estática del orden predominante en la estética clásica y que inspira los conceptos fijos de los grados estéticos, opone el concepto dinámico de libertad, que al par que los explica, restablece la profunda continuidad de la vida artística.

La misma tendencia informa los bellos estudios sobre las ideas de orden y de libertad en la historia del pensamiento humano. Investigación que revela la prolongada persistencia del intelectualismo helénico que determina la atribución de la más alta gerarquía al orden y la escasa importancia concedida a la verdadera libertad.

$Y$ es que todo intelectualismo tiene una inclinación inevitable a la práctica y a la exterioridad. De allí que su especulación refleje más bien las modalidades de la realidad externa que las exigencias interiores del espíritu. De alí también que toda su actividad se dirija, ora a construir sistemas cuya coherencia satisfaga su necesidad lógica, ora a establecer un orden que garantice la eficacia de la acción. En uno y en otro caso desconoce la expansión creadora, el impulso vital de la conciencia. 
sobre todo de profesores conscientes de su función social, sin elementos materiales de desarrollo, las escuelas primarias suelen ser organismos anémicos, donde bajo el imperio de las viejas rutinas, se recibe una enseñanza memorista y vaci:a.

Pero hay en el problema un aspecto más serio, y el haberlo señalado, confiere su originailidad de trascendencia a la orientación educativa que adopta el doctor Deustua. Según él la transformación moral no puede venir del pueblo; debe iniciarse en las clases dirigentes como ideal y como disciplina.

Pero la educación preferente y previa de las clases directoras se impone todavía por ina razón lógica. Porque, en efecto: ¿ cómo hemos de educar al pueblo si no conocemos sus necesidades, sus disposiciones mentales y morales? Toda educación es ideal y luego disciplina, dirección. ¿Y cómo hemos de educar si no tenemos ideal, si ignoramos las energías, las fuerzas, las corrientes que debemos encauzar y dirigir? Precisa pues, antes que todo, la formación de los educadores, de quienes ihatic deeforjareel ideaby realizarlo, más que con las luces des la dinteligencia, conelas energía generosa de su corazón.

$\mathrm{Y}$ es la universidad quien debe formarlos. A ella corresponde pucs la concepción ideal de nuestro destino, la inteligencia profunda e incansable de la propia realidad, la actividad ordenadora y sintética de la vida nacional. A ella convergerán todos los estímulos vitales y de ella partirán convertidos en cultura, transformados en espíritu. En ella se enseñará la ciencia, pero sobre todo se comunicará el anhelo ideal que inspira a los apóstoles.

Mas, ¿cíál ha de ser el contenido espiritual de esa educación. A resolver esa pregunta se dirigen los trabajos que el doctor Detustua ha escrito a propósito de un cuestiona- 
rio sobre la ley de instrucción y que constituyen sin duda el esfuerzo más importante de la ideología nacional sobre el problema educativo.

Siento no hacer ia cietenida exposición que estos trabajos se merecen. Por ahora retendré simplemente sus puntos de vista más saltantes y sus tendencias más características. Pónese ante todo de relieve el carácter filosófico de las disciplinas pedagógicas'. La ciencia explica los hechos, pero la determinación de los valores le corresponde a la filosofía y toda educación debe partir de una previa determinación de valor. Para satisfacer esa exigencia el doctor Deustua se pregunta: "qué conviene más: ¿una dirección científica naturalista con finalidad exclusivamente económica, una religiosa, espiritualista, con finalidad exclusivamente sobrenatural o una filosofía idealista, que concilie ambas tendencias y forme el carácter moral del educando?" Ya vimos que el maestro preconiza esta última, pues sólo ella puede poner a salvo la libertad que es la premisa indispensable de toda cultura verdadera. Esa educación ha de refererirse de preferencia al sentimie̊nto dintine resorte gle la vida, fuego interior del alma.jorge Puccinelli Converson

La libertad como ideal, la libertad como criterio valuador y como pura expresión del espíritu: he ahí el motivo fundamental que el doctor Deustua desenvuelve en páginas donde el rigor de los análisis no perjudica el entusiasmo lírico ni empaña la visión ideal, en que se junta el agudo sentimiento de las dificultades a la clara percepción de los remedios, donde finalmente, se propone un amplio concepto de cultura ítil sobre todo entre nosotros que faltos de tradiciones intelectuales, necesitamos nuestros puntos de apoyo ideológicos en una abundante riqueza espiritual. 
En resumen, creemos descubrir tres motivos fundamentales en la obra filosófica y educacional de Deustua a saber: primero, la libertad es la esencia de la vida espiritual; segundo, existe un mundo de valores en cuya gerarquía ocupa el valor 'estético el lugar supremo y cuya aprehensión no puede ser realizada por la aptitud lógica sino por el sentimiento; tercero, la obra educativa debe fundarse sobre una viva intuición de los altos valores del espíritu y debe ser la obra de una élite formada en la universidad y que junte a la conciencia de su responsabilidad el conocimiento de los factores sociológicos y de las tendencias morales del país.

La doctrina de Deustua sobre la libertad no es una mera concepción metafísica sino más bien el resultado de una experiencia psicológica. Alidentificar, con profundo sentido, libertad e imaginación y al considerar esta última como la vida misma del ser espiritual, Deustua propone una psicología opuesta por igual al determinismo científico y al racionalismo metafísico y que al par que reivindica la espontaneidad creadora dẻdai actividadepsíquica sa concibe como una actividad de ēxpresión, idelcónfiguración y de síntesis. Por eso toda genuina actividad del alma es, por esencia, de carácter estético. Y por ello igualmente en el arte libre encuentra el hombre la más auténtica, verdadera y plena realización de sí mismo.

Pero hay más: la experiencia psicológica y estética de la libertad que condensa, expresa y vive en cada creación la totalidad de la vida psíquica, suscita en, el maestro una admirable concepción sobre el ideal de la cultura que no debe ser ni exclusivamente objetiva y estática ni exclusivamente subjetiva y dinámica sino integral y armónica, de suerte que en ella todas las energías de la existencia encuentren su realización adecuada y perfecta. "Presente, pasado y fu- 
turo, escribe, constituyen la melodía del tiempo que no se pirede destruir sin correr el riesgo de no comprender bien la vida y de encaminarla por senderos que conducen a la ruina. Hacer del amor el impulso más poderoso de la voluntad; dirigir ésta por el pensamiento penetrado de realidad; mantener estrechamente unidos el esfuerzo interno de la conciencia y su forma de actividad exterior; concordar todos los valores espirituales en una síntesis que comprenda la totalidad de la vida, esas deben ser las aspiraciones de la cultura en que la libertad y el orden se compenetren, desapareciendo las aparentes antinomias entre pensamiento y sentimiento, individuo y comunidad, nacionalismo y humanismo que mantienen todavía la anarquía en, el mundo". ( I).

Dentro de su inspiración psicológica fundamental que confiere a los aspectos subjetivos del alma una importancia predominante, Deustua sostiene que no es el pensamiento lógico sino el sentimiento quien aprehende y vive los valores espirituales, Doctrina afín a la sostenida por Max Scheller sobre lal intulién entoeional delos valores y que, cuando fué expuresta Pètre chósotroser, hace más de veinte años, constituyó una novedad de sumo interés, tanto porque asignaba al sentimiento una eminente capacidad de intuición y orientación, cuanto porque implicaba una concepción del valor como un mundo sustraído a las determinaciones de la pura lógica y capaz, sin embargo, de proponer a la vida religiosa, moral y estética normas e ideales de la más alta espirituaiidad.

Es sin duda discutible la concepción de Deustua cn cuanto asigna al valor estético el lugar supremo en la gerarquía de los valores. Por nuestra parte creemos que ese lugar le corresponde al valor religioso. Pero es innegable la

(1) La Cultura Nacional, Lima 1927. pág. 149. 
profunda significación filosófica de su doctrina puesto que la vida estética es la forma de actividad en que se realizan con mayor frescura y autenticidad las virtualidades creadoras de la vida y aquella en que, por decirlo así, se hace visible, luminoso, esplendente el oscuro misterio del mundo.

La pedagogía debe fundamentarse sobre el sentimiento de los valores y dirigir la vida hacia la conquista de la libertad y de la plenitud interior. Por lo tanto la obra pedagógica no realiza sus fines mediante la simple difusión del saber ni mucho menos por virtud de la simple multiplicación de las escuelas primarias. La obra de la educación es una tarea de cultura superior, de dirección espiritual, de iluminación, que sólo puede venir de espíritus educados ellos mismos en una atmósfera elevada y en el grave sentimiento de una misión por realizar. Tales ideas envuelven la exigencia de prestar atención especial a la educación de las clases dirigentes ya que de ellas parten para difundirse con resultados benéficos o adversos los impulsos psicológicos y morales de 1 boblectividad. Yeasi dicedgeustua con frase elocuente: "Cuando la influenciai delnmedio, es adversa a la constitución de un estado moral, sólo un impulso espontáneo y vigoroso de la clase dirigente puede evitar el desastre fatal en la vida de la colectividad. Creer que, en ese caso, la salvación puede resultar de un movimiento inconsciente de abajo a arriba es tener un concepto equivocado de la organización social, es comparar la vida colectiva de los hombres, en su desarroilo, a la estructura arquitectónica que se atribuye a la Naturaleza. La organización social no es un edificio; y si lo fuera, sería un edificio que comienza a construirse por la cima, bajo la dirección de un arquitecto colocado en la altura. Esa comparación adoptada por el pensamiento estático antiguo, no es exacta. Si puede compararse la progresiva constitución social con la activdad artísti- 
ca, debería buscarse la analogía en la Música; porque la vida social, el alma nacional es el desarrollo de un tema que brota libremente en el alma de los que asumen la dirección de esa fuerza psíquica colectiva, que persigue fines trascendentales y se modela en armonía con ellos ( I ).

Contemplada en la armonía de su tres motivos fundamentales la obra de Deustua se nos ofrece no tan sólo como una teoría, sino también como un criterio de acción, como un ideal. En cuanto teoría, afirma la libertad como la esencia misma de la vida; en cuanto ideal propone la actividad fecunda, la creación de nutevas realidades, la conquista de horizontes cada vez más yastos. Y de esta suerte el doctor Deustua podría quizá decir que es necesario hacer de la vida una obra de arte, pero no en el sentido de la plástica que innoviliza las formas para la contemplación, sino más bien en el sentido de la lírica que concilia, con la incesante renovación de sus expresiones, $\mathrm{CP}$ permanenêa psicológica y metafísica del imptesofeftidamentalodedassida.

Mariano Iberico

(1) Obra citada, pág. 369. 